NASA/TM-2005-213554

\title{
Demonstration of an X-Band Multilayer Yagi-Like Microstrip Patch Antenna With High Directivity and Large Bandwidth
}

James A. Nessel, Afroz Zaman, and Richard Q. Lee Glenn Research Center, Cleveland, Ohio

Kevin Lambert

Analex Corporation, Brook Park, Ohio 
Since its founding, NASA has been dedicated to the advancement of aeronautics and space science. The NASA Scientific and Technical Information (STI) Program Office plays a key part in helping NASA maintain this important role.

The NASA STI Program Office is operated by Langley Research Center, the Lead Center for NASA's scientific and technical information. The NASA STI Program Office provides access to the NASA STI Database, the largest collection of aeronautical and space science STI in the world. The Program Office is also NASA's institutional mechanism for disseminating the results of its research and development activities. These results are published by NASA in the NASA STI Report Series, which includes the following report types:

- TECHNICAL PUBLICATION. Reports of completed research or a major significant phase of research that present the results of NASA programs and include extensive data or theoretical analysis. Includes compilations of significant scientific and technical data and information deemed to be of continuing reference value. NASA's counterpart of peerreviewed formal professional papers but has less stringent limitations on manuscript length and extent of graphic presentations.

- TECHNICAL MEMORANDUM. Scientific and technical findings that are preliminary or of specialized interest, e.g., quick release reports, working papers, and bibliographies that contain minimal annotation. Does not contain extensive analysis.

- CONTRACTOR REPORT. Scientific and technical findings by NASA-sponsored contractors and grantees.
- CONFERENCE PUBLICATION. Collected papers from scientific and technical conferences, symposia, seminars, or other meetings sponsored or cosponsored by NASA.

- SPECIAL PUBLICATION. Scientific, technical, or historical information from NASA programs, projects, and missions, often concerned with subjects having substantial public interest.

- TECHNICAL TRANSLATION. Englishlanguage translations of foreign scientific and technical material pertinent to NASA's mission.

Specialized services that complement the STI Program Office's diverse offerings include creating custom thesauri, building customized databases, organizing and publishing research results ... even providing videos.

For more information about the NASA STI Program Office, see the following:

- Access the NASA STI Program Home Page at http://www.sti.nasa.gov

- E-mail your question via the Internet to help@sti.nasa.gov

- Fax your question to the NASA Access Help Desk at 301-621-0134

- Telephone the NASA Access Help Desk at 301-621-0390

- Write to:

NASA Access Help Desk

NASA Center for AeroSpace Information 7121 Standard Drive

Hanover, MD 21076 
NASA/TM-2005-213554

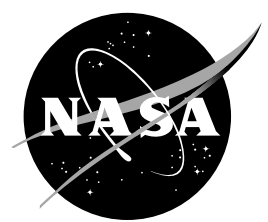

\section{Demonstration of an X-Band Multilayer Yagi-Like Microstrip Patch Antenna With High Directivity and Large Bandwidth}

James A. Nessel, Afroz Zaman, and Richard Q. Lee

Glenn Research Center, Cleveland, Ohio

Kevin Lambert

Analex Corporation, Brook Park, Ohio

Prepared for the

International Symposium on Antennas and Propagation and USNC/URSI National Radio Science Meeting sponsored by the Institute of Electrical and Electronics Engineers Washington, DC, July 3-8, 2005

National Aeronautics and Space Administration

Glenn Research Center 


\section{Acknowledgments}

Special thanks to Dr. Félix A. Miranda for all his helpful discussions and suggestions.

This report is a preprint of a paper intended for presentation at a conference. Because of changes that may be made before formal publication, this preprint is made available with the understanding that it will not be cited or reproduced without the permission of the author.

Trade names or manufacturers' names are used in this report for identification only. This usage does not constitute an official endorsement, either expressed or implied, by the National Aeronautics and Space Administration.

Available from

NASA Center for Aerospace Information 7121 Standard Drive

Hanover, MD 21076
National Technical Information Service 5285 Port Royal Road Springfield, VA 22100 


\title{
Demonstration of an X-Band Multilayer Yagi-Like Microstrip Patch Antenna With High Directivity and Large Bandwidth
}

\author{
James A. Nessel, Afroz Zaman, and Richard Q. Lee \\ National Aeronautics and Space Administration \\ Glenn Research Center \\ Cleveland, Ohio 44135 \\ Kevin Lambert \\ Analex Corporation \\ Brook Park, Ohio 44142
}

\begin{abstract}
The feasibility of obtaining large bandwidth and high directivity from a multilayer Yagi-like microstrip patch antenna at $10 \mathrm{GHz}$ is investigated. A measured 10-dB bandwidth of $\sim 20$ percent and directivity of $\sim 11 \mathrm{dBi}$ is demonstrated through the implementation of a vertically-stacked structure with three parasitic directors, above the driven patch, and a single reflector underneath the driven patch. Simulated and measured results are compared and show fairly close agreement. This antenna offers the advantages of large bandwidth, high directivity and symmetrical broadside patterns, and could be applicable to satellite as well as terrestrial communications.
\end{abstract}

\section{Introduction}

Despite many attractive features like low profile, low cost, and ease of solid state device integration, microstrip patch antennas are limited by their inherently narrow bandwidths and low directivity. Previous attempts to overcome these deficiencies have resulted in substantial success. Larger bandwidths have been achieved through clever use of shorting walls, shaped slots, and electromagnetically coupled patches, while higher directivities have been realized with parasitic patches or high permittivity substrates (refs. 1 to 3). However, most previous attempts were focused on the enhancement of either the bandwidth or directivity. Thus, it would be beneficial to simultaneously improve both of these parameters to increase the versatility of the patch antenna.

Planar Yagi arrays with patch antennas as driven and parasitic elements have been reported earlier (refs. 4 and 5). These antennas produce end-fire radiation and a four-element array of such antennas has been introduced for mobile satellite communications applications (ref. 5). In ground-to-space communications, however, an antenna with a broadside beam is required, and high directivity and large bandwidth are necessary to support high data rate communication. In this paper, a unique multilayer Yagi-like microstrip antenna is presented which simultaneously addresses these aforementioned requirements.

\section{Antenna Design and Optimization}

The antenna structure under examination is illustrated in figure 1. Verification that this structure is conceptually similar to a Yagi antenna was performed by varying the number of stacked directors and analyzing its radiation pattern at each increment. As more directors were added, the antenna's beamwidth narrowed, indicating higher directivity. Simulations performed using Zeland's IE3D electromagnetic simulator showed that maximum directivity was achieved with three directors and that further stacking had little effect on performance enhancement. 


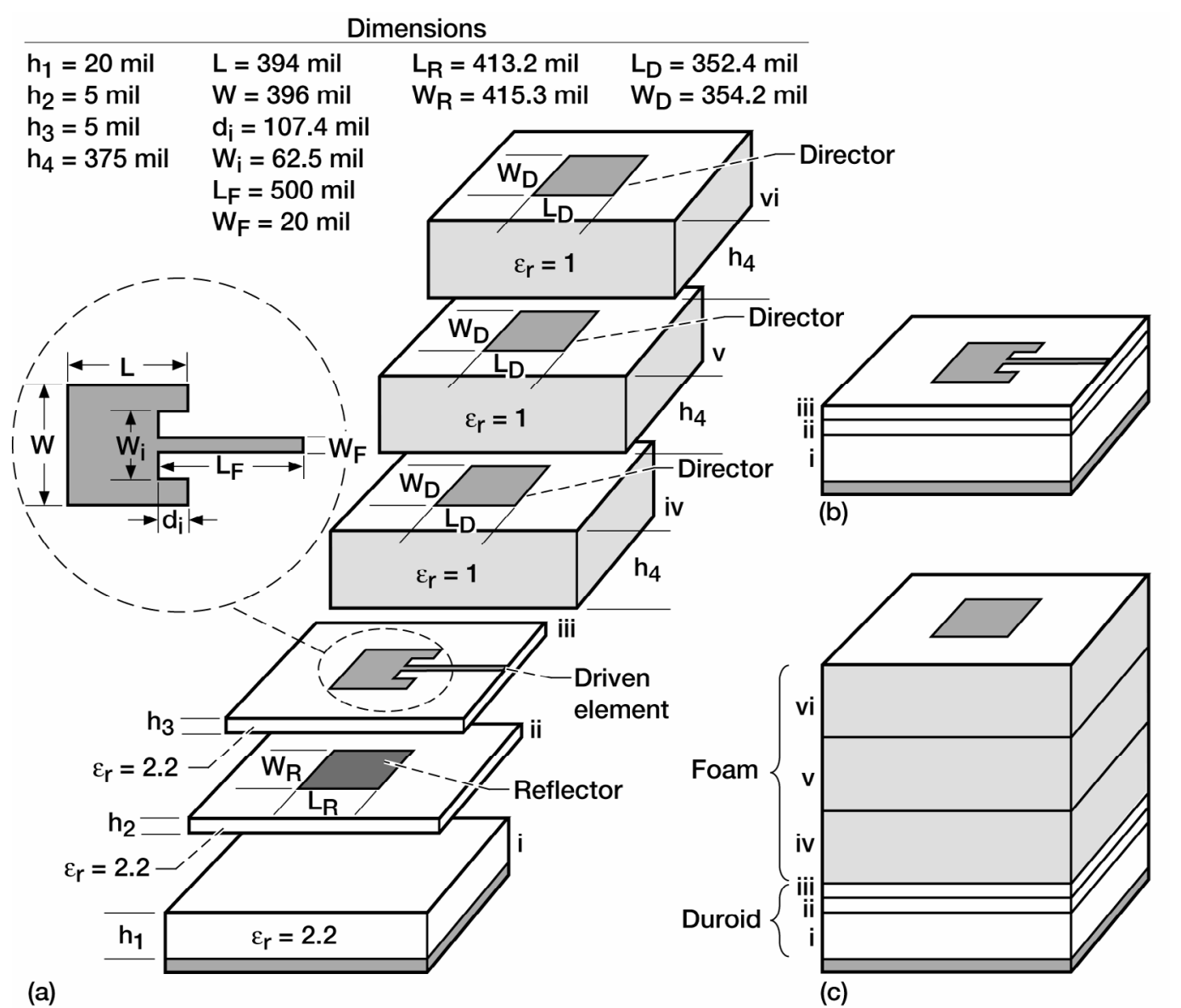

Figure 1.-Multilayer patch antenna and its assembly sequence. (a) Exploded 3D view showing the individual layers of the antenna. (b) Partially assembled antenna (without directors).

(c) Complete assembled antenna (substrate and directors).

The directors' size and spacing of approximately $0.8 A$ and $0.3 \lambda_{0}$, respectively, were baselined from previous designs (ref. 4), where $A$ represents the area of the driven patch, and $\lambda_{0}$ is the free space wavelength. For a copper reflector, baseline size and spacing was determined to be $1.1 \mathrm{~A}$ and $0.35 \lambda_{0}$, respectively (ref. 4). The investigation presented herein was performed, however, utilizing a lower conductivity material for the reflector (AgHT-8, $\sigma \approx 5 \times 10^{4} \mathrm{~S} / \mathrm{m}$ ). This material was chosen because it was readily available in our laboratory. The multilayer structure was optimized with IE3D based on the AgHT-8 material and 5 and 20 mil thick Duroid ${ }^{\circledR}$ substrates $\left(\varepsilon_{\mathrm{r}}=2.2\right)$. From table 1 , it can be observed that changing the conductivity of the reflector in the optimized design results in degradation of bandwidth and/or directivity.

TABLE 1.-IE3D SIMULATED REFLECTOR CONDUCTIVITY EFFECTS ON ANTENNA PERFORMANCE

\begin{tabular}{cccc}
\hline Conductivity (S/m) & Resonant Frequency (GHz) & 10-dB BW & Directivity (dBi) \\
\hline $5 \times 10^{7}$ & 10.4 & $1.4 \%$ & 12.4 \\
$5 \times 10^{6}$ & 10.3 & $1.9 \%$ & 12 \\
$5 \times 10^{5}$ & 10.3 & $2.6 \%$ & 12.2 \\
$1 \times 10^{5}$ & 10.2 & $8.1 \%$ & 11.95 \\
$5 \times 10^{4}$ & 9.8 & $12.8 \%$ & 11.8 \\
$2.5 \times 10^{4}$ & 9.9 & $11.6 \%$ & 11.3 \\
$1 \times 10^{4}$ & 10 & $8.2 \%$ & 11.6 \\
\hline
\end{tabular}




\section{Antenna Fabrication}

The patch antenna was first patterned on a 5 mil thick Rogers Duroid ${ }^{\circledR} 5880\left(\varepsilon_{\mathrm{r}}=2.2,1 / 2\right.$ oz. copper $)$ substrate. A second 5 mil layer was formed with a rectangular shape cut out and centered below the driven patch for reflector placement. Still a third 20 mil thick layer of the same material, with a ground plane, was placed underneath this reflector patch. The three layers were sandwiched together to form the partially assembled antenna structure (see fig. 1(b)) with total substrate thickness of 30 mils and mounted on a plastic fixture. Separation between the directors, also made from 5 mil thick Rogers Duroid ${ }^{\circledR} 5880$, and the driven patch were accomplished with $3 / 8$ inch foam spacers $\left(\varepsilon_{\mathrm{r}} \approx 1\right)$. Transparent adhesive was wrapped around the entire structure to keep the multiple layers together. A photograph of the fabricated multilayer patch antenna is shown in figure 2 .

\section{Simulated/Measured Results and Discussion}

The simulated 10-dB bandwidth was found to be approximately 13 percent with an associated directivity of $11.8 \mathrm{dBi}$ (see fig. 3).

The return loss of the fabricated design was measured using an Agilent 8510C Vector Network Analyzer, and the results are compared with simulation results as shown in figure 3 . The measured 10-dB bandwidth was about 20 percent. Discrepancies between measurement and simulation are possibly attributable to slight differences in the actual physical properties of the lossy reflector as compared with those simulated on IE3D.

The antenna's radiation pattern was measured in NASA Glenn Research Center's Cylindrical Near Field Range Facility. Comparisons of the simulated and measured radiation pattern for the E-plane and H-plane cuts are shown in figures 4 and 5, respectively. Close agreement between the simulated and measured patterns is observed. The maximum directivity is calculated from equation (1), where $P(\theta)$ is the power radiated by the antenna, and is found to be $11.3 \mathrm{dBi}$, which agrees with the simulated value.

$$
D=\frac{1}{\frac{1}{4 \pi} \int_{0}^{2 \pi \pi / 2} \int_{0}^{2} P(\theta) \sin (\theta) d \theta d \phi}
$$

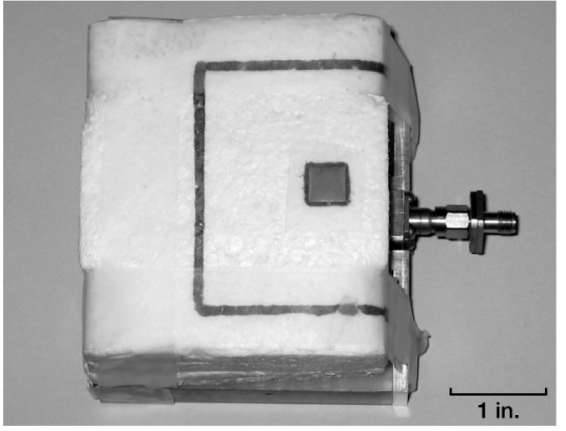

Figure 2.-Photo of fabricated multilayer patch antenna.

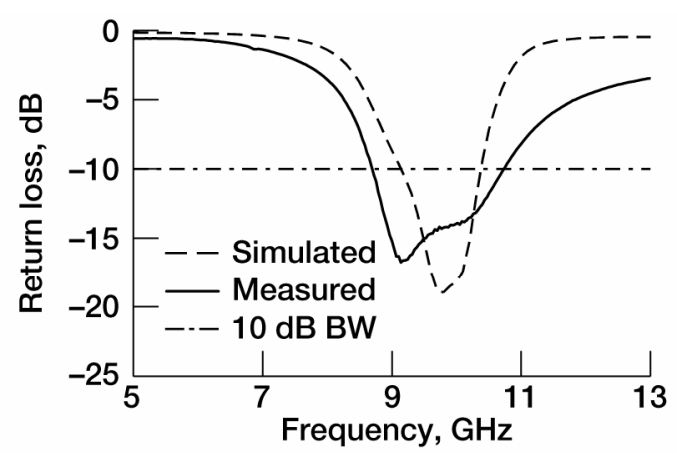

Figure 3.-Comparison of measured and simulated return loss for multilayer patch antenna. 


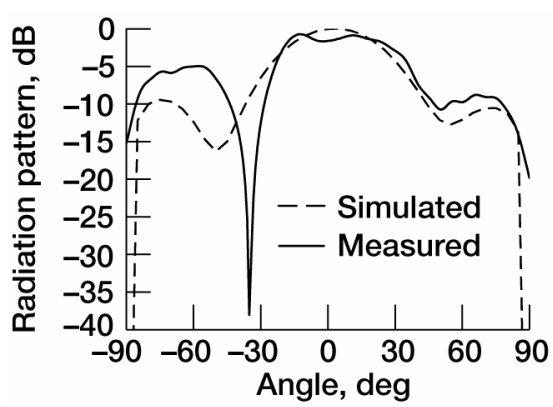

Figure 4.-Comparison between measured and simulated far field E-plane radiation pattern.

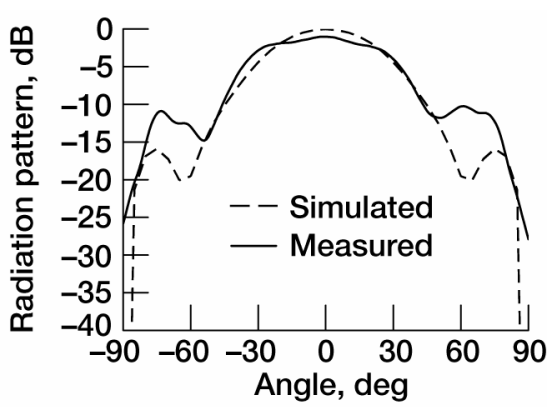

Figure 5.-Comparison between measured and simulated far field $\mathrm{H}$-plane radiation pattern.

\section{Conclusions}

A directivity- as well as bandwidth-enhancement scheme, based on a vertically-stacked microstrip Yagi-like antenna is demonstrated. The antenna was analyzed via computer simulations and experimental measurements. Simulated as well as measured results show that this structure allows for high bandwidth while simultaneously maintaining a broadside beam of high directivity. Future work on this antenna will focus on design optimization for enhancement of these parameters. Application of this design concept to develop miniaturized antennas at S-band frequencies for surface-to-surface wireless lunar/mars communications is being investigated.

\section{References}

1. A.K. Shackelford, K.F. Lee, and K.M. Luk, "Design of Small-Size Wide-Bandwidth Microstrip-Patch Antennas," IEEE Antennas and Propagation, Vol. 45, No. 1, pp. 75-83, Feb. 2003.

2. R.Q. Lee and K.F. Lee, "Experimental Study of the Two-Layer Electromagnetically Coupled Rectangular Patch Antenna," IEEE Transactions on Antennas and Propagation, Vol. 38, No. 8, pp. 1298-1302, Aug. 1990.

3. S. Aditya, C.K. Sim, D. Wu, W.T. Chua, Z.X. Shen, and C.L. Law, "High-Gain 24-GHz CPW-fed Microstrip Patch Antennas on High-Permittivity Substrates," Antennas and Wireless Propagation Letters, Vol. 3, Iss. 3, pp. 30-33, 2004.

4. J. Huang, "Microstrip Yagi Array Antenna for Mobile Satellite Vehicle Application," IEEE Transactions on Antennas and Propagation, Vol. 39, No. 7, pp. 1024-1030, July 1991.

5. S.K. Padhi and M.E. Bialkowski, "Parametric Study of a Microstrip Yagi Antenna," Asia-Pacific Microwave Conference, pp. 715-718, Dec. 2000. 


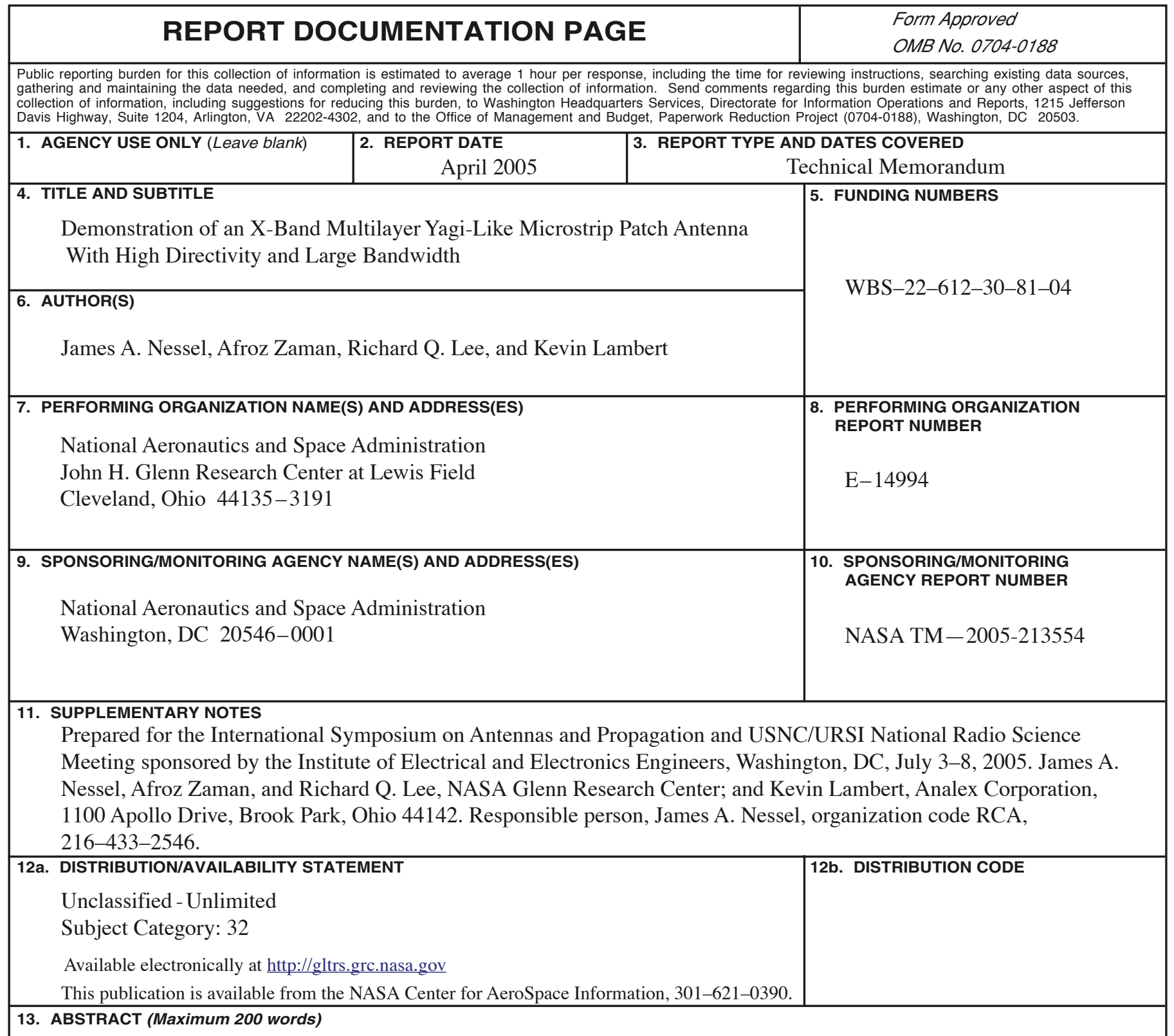

The feasibility of obtaining large bandwidth and high directivity from a multilayer Yagi-like microstrip patch antenna at $10 \mathrm{GHz}$ is investigated. A measured 10-dB bandwidth of $\sim 20$ percent and directivity of $\sim 11 \mathrm{dBi}$ is demonstrated through the implementation of a vertically-stacked structure with three parasitic directors, above the driven patch, and a single reflector underneath the driven patch. Simulated and measured results are compared and show fairly close agreement. This antenna offers the advantages of large bandwidth, high directivity, and symmetrical broadside patterns, and could be applicable to satellite as well as terrestrial communications.

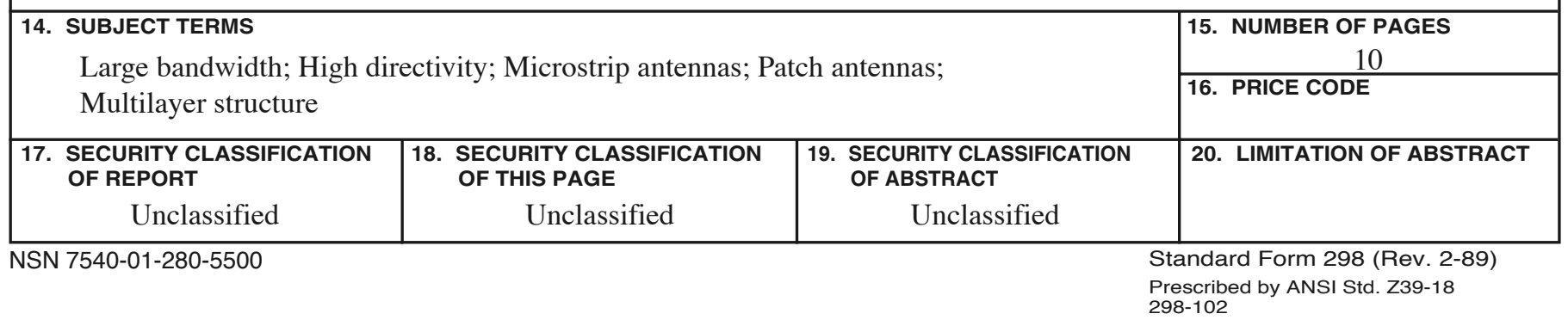



